\title{
MEDIDAS PREVENTIVAS PARA O ENFRENTAMENTO DA COVID-19 EM UM SERVIÇO DE ALIMENTAÇÃO INSTITUCIONAL NA CIDADE DE FORTALEZA - CE
}

\author{
Herison Leandro Mendonça da Silva, Diana Valesca Carvalho, Ana Erbênia Pereira Mendes
}

Universidade Federal do Ceará - UFC

DOI: $10.21439 /$ conexoes.v15i0.1987

\begin{abstract}
Resumo. A pandemia de Covid-19, ocasionada pelo novo coronavírus, trouxe graves consequências para os serviços de alimentação. Os Restaurantes Institucionais tiveram que revisar procedimentos, pois, apesar dos alimentos serem considerados improváveis veículos de transmissão do coronavírus, a transmissão pode ocorrer através do contato físico entre manipuladores de alimento. O objetivo deste estudo é relatar as medidas preventivas implementadas por um restaurante institucional situado em FortalezaCe. O estudo foi realizado de janeiro a abril de 2020, através da observação visual e acompanhamento das atividades implementadas para mitigar os riscos de contaminação por Covid-19. A observação e a descrição das condutas foram realizadas por sete diferentes setores do restaurante. $\mathrm{O}$ instrumento utilizado para a observação foi o check list do próprio setor, elaborado com base na lista de verificação das boas práticas em serviços de alimentação, conforme Resolução n. ${ }^{\circ} 216$ de 15 de setembro de 2004. O resultado da pesquisa apresenta as principais medidas de enfrentamento ao vírus nos diversos setores do estabelecimento. A diretoria da empresa juntamente com a equipe técnica do restaurante elaborou um documento intitulado "Medidas de Prevenção ao Covid-19". O documento enumera ações que foram implementadas nos diversos setores do restaurante, com a finalidade de evitar o contágio do Covid-19 entre manipuladores e comensais, e garantir a segurança alimentar em todas as etapas de produção. Pode-se concluir que as medidas adotadas pelo restaurante estão de acordo com os órgãos de saúde, e possuem eficácia na prevenção à contaminação de manipuladores e comensais por COVID-19.
\end{abstract}

Palavras-chaves: COVID-19. Serviços de alimentação. Higiene dos alimentos.

\section{PREVENTIVE MEASURES TO COMBAT COVID-19 IN INSTITUTIONAL FOOD SERVICE IN FORTALEZA CITY - CE}

\begin{abstract}
The Covid-19 pandemic, caused by the new coronavirus, had severe consequences for food services. Institutional Restaurants had to review procedures. Although food is considered unlikely to transmit the coronavirus, transmission can occur through physical contact among food handlers. The aim of this study is to report the preventive measures implemented by an institutional restaurant located in Fortaleza-Ce. The study was carried out from January to April 2020, through visual observation and monitoring of the implemented protocols to mitigate the risks of contamination by Covid-19. The observation and description of the behaviors were carried out by seven different sectors of the restaurant. The instrument used for observation was the sector's own checklist, prepared based on the checklist of good practices in food services, according to Resolution No. 216 of September 15, 2004. The study presents the main measures to prevent the virus in the various sectors of the establishment. The company's board, together with the restaurant's technical team, prepared a document entitled "Covid-19 Prevention Measures". The document lists actions that have been implemented in the various sectors of the restaurant, with the aim of preventing the spread of Covid-19 between handlers and diners, and guaranteeing food safety at all stages of production. It can be concluded that the measures adopted by the restaurant are in accordance with the national and international health authorities, and are effective in preventing the contamination of handlers and diners by COVID-19.
\end{abstract}

Keywords: COVID-19, food services, food hygiene. 


\section{INTRODUÇÃO}

Durante o ano de 2020 uma palavra, até então incomum ou desconhecida, começou a fazer parte do vocabulário da população mundial, a palavra Pandemia, que conforme a Organização Mundial da Saúde (OMS), define uma moléstia, doença ou ameaça de alcance global e grandes proporções. O termo é utilizado quando uma epidemia - grande surto que afeta uma região se espalha por diferentes continentes, com transmissão sustentada de pessoa para pessoa (WHO, 2020).

A COVID-19 é uma doença infecciosa causada por um novo corona vírus, denominado SARS-CoV-2, pertencente à família Coronaviridae (FIOCRUZ, 2020). Os dados indicam que esse vírus infectou pessoas de mais de 190 países em menos de 4 meses, inclusive no Brasil. Os sintomas mais comuns incluem febre, cansaço e tosse seca, além de outros sintomas como falta de ar, dores no corpo, dor de garganta e algumas poucas pessoas relatam diarreia, náusea ou coriza (WHO, 2020). A transmissão acontece de uma pessoa doente para outra ou por contato próximo por meio do toque do aperto de mão, gotículas de saliva, secreções e objetos e superfícies contaminadas. As medidas mais eficazes de contenção do vírus e diminuição do contágio consistem em isolamento social, proibir aglomeração de pessoas e, principalmente, a adoção de hábitos rigorosos de higiene pessoal (BRASIL, 2020b).

Tais medidas implicaram em mudanças nos serviços de alimentação que tiveram que se adaptar rapidamente para essa nova realidade. As normativas publicadas até o dia 23 de março de 2020 catalisaram o fechamento de muitos estabelecimentos de refeições coletivas e a migração de outros tantos para os serviços de take out/away e delivery (OLIVEIRA; ABRANCHES; LANA, 2020). Essa adaptação dos serviços teve como foco principal a sobrevivência desse setor da economia no momento de crise (BRASIL, 2020b). Somente a partir do dia 22 de junho os restaurantes de Fortaleza tiveram autorização para funcionar através do atendimento presencial, mas respeitando algumas regras, como horários reduzidos, redução da capacidade, distanciamento das mesas, além do uso obrigatório de máscaras e aferição da temperatura dos clientes (CEARÁ, 2020). Apesar dessas mudanças ocorridas, alguns restaurantes tiveram autorização para manter suas atividades, mesmo em tempos de pandemia. É o caso dos restaurantes institucionais que operam dentro de instituições e empresas consideradas essenciais fornecendo alimentação para os colaboradores.

Mesmo que os alimentos sejam considerados improváveis veículos de transmissão do vírus da COVID-19, ele pode ser transmitido entre os manipuladores, ou des- ses para os comensais através do contato próximo ou de objetos contaminados, caso não sejam atendidas as orientações de higiene pessoal, segurança alimentar e distanciamento entre pessoas, recomendadas pelo Ministério da Saúde e pela Agência Nacional de Vigilância Sanitária - ANVISA (BRASIL, 2020a). Sendo assim, torna-se necessário trazer para o meio acadêmico a discussão sobre a prevenção do contágio por COVID-19 nos serviços de alimentação, promovendo e apoiando ações de enfrentamento que contemplem essa temática, sobretudo no âmbito das organizações.

Portanto, o objetivo deste estudo é relatar as medidas preventivas e protetivas implementadas por um restaurante institucional situado na cidade de FortalezaCE, com a finalidade de evitar o contágio do COVID19 entre manipuladores de alimentos e comensais, bem como, garantir a segurança alimentar em todas as etapas de produção no restaurante.

\section{MÉTODO}

O estudo realizou-se entre os meses de janeiro a abril de 2020, através da observação visual e acompanhamento de todas as atividades desenvolvidas em um Restaurante Institucional situado na cidade de Fortaleza$\mathrm{Ce}$, considerando o mês de janeiro como antes da pandemia e o mês de abril, durante pandemiado coronavírus. A observação e a descrição das condutas foram realizadas por setores do restaurante, a saber:

(I) Área administrativa e contábil;

(II) Almoxarifado;

(III) Açougue;

(IV) Cozinha;

(V) Refeitório;

(VI) Copa;

(VII) Depósito de materiais.

O instrumento utilizado para a observação foi o check list de cada setor, elaborado com base na lista de verificação das boas práticas em serviços de alimentação, conforme resolução n. ${ }^{\circ} 216$ de 15 de setembro de 2004 (BRASIL, 2004).

A seguir serão apresentadas as medidas adotadas pelo estabelecimento para solucionar as desconformidades identificadas. O compartilhamento das informações contidas neste artigo foi autorizado e motivado pela direção do local onde a pesquisa foi realizada. 


\section{RESULTADOS E DISCUSSÃO}

A unidade de alimentação e nutrição (UAN) de um restaurante institucional, além de outras atividades, desempenha a importante função de fornecer refeições seguras aos seus colaboradores. O restaurante estudado funciona vinte e quatro horas por dia, com uma produção diária de aproximadamente1000 refeições, divididas entre café da manhã, almoço, jantar e ceia. A UAN em estudo está dividida em sete setores: (I) Área administrativa e contábil, (II) Almoxarifado, (III) Açougue, (IV) Cozinha, (V) Refeitório, (VI) Copa (VII) Depósito de materiais. Cada setor possui um encarregado, responsável por colocar em prática as ordens emanadas pela diretoria do estabelecimento.

Antes da pandemia, as não conformidades observadas foram a presença de avarias estruturais e o descumprimento de hábitos de higiene na manipulação de alimentos. Como exemplo se pode citar a existência de rachaduras no piso e na parede das áreas de produção; a existência de pias e/ou chuveiros interditados por defeito nas instalações sanitárias; e a verificação de hábitos pessoais inadequados durante a manipulação de alimentos, como conversas desnecessárias e a não utilização do uniforme completo durante a jornada de trabalho.

Visando oferecer segurança para os trabalhadores e para os comensais que frequentam diariamente o estabelecimento, no início da pandemia por COVID-19, foram realizados estudos preliminares que apontassem os pontos a serem corrigidos, de modo que, fosse mitigada a disseminação da doença no serviço de alimentação. A aplicação de Check List apontava a necessidade de correção das seguintes desconformidades:

- livre acesso às dependências internas de pessoas não funcionárias;

- desinformação e veiculação de informações inverídicas a cerca da doença;

- compartilhamento de temperos, portaguardanapos, entre outros;

- aglomeração e confinamento de funcionários em ambientes fechados;

- quantidade irrestrita de pessoas por mesa e de pessoas ao mesmo tempo no refeitório;

- quantidade insuficiente de EPIs e face Shields;

- insegurança e medo por parte dos funcionários.

A partir do conhecimento dessa pandemia e das possíveis consequências para o quadro de funcionários, a diretoria da empresa se reuniu com os responsáveis técnicos pelo restaurante que juntos elaboraram um documento intitulado "Medidas de Prevenção ao Covid-19". $\mathrm{O}$ documento enumera ações que devem ser postas em prática nos diversos setores do restaurante, visando o alcance dos seguintes objetivos: Evitar aglomeração de colaboradores e comensais; Evitar que colaboradores com sintomas gripais tenham contato com os demais; Garantir a provisão de Equipamentos de Proteção Individual (EPIs) e o uso responsável; Evitar que visitantes e fornecedores comprometam a Segurança Alimentar; Evitar que funcionários que atuem nas zonas de contato, como o pessoal que trabalha na enfermaria da empresa, tenha contato com os demais; Afastar colaboradores pertencentes ao chamado grupo de risco; Evitar o clima de pânico e a desmotivação e baixa de moral dos funcionários; Evitar o desabastecimento de insumos; Evitar o absenteísmo e a perda de capacidade produtiva; Evitar o contágio entre colaboradores ou entre estes e os comensais; Revisar e criar novos POPs (Procedimentos Padronizados Operacionais); Adquirir em critério de urgência instrumentos necessários ao combate e à prevenção da disseminação interna do Coronavírus; Entre outros.

Muitas medidas afirmadas já fazem parte da rotina do restaurante, contudo, devido a importância que exercem na Higiene e Segurança dos Alimentos acabaram sendo enfatizadas também no documento criado para o enfrentamento ao coronavírus. As medidas preventivas e protetivas são apresentadas abaixo, divididas por setores do restaurante. A responsabilidade de colocar em prática tais medidas é do encarregado de cada subseção.

\subsection{Subseção administrativa e contábil}

Responsável pela administração do pessoal, das finanças, e pela liquidação de notas fiscais e elaboração de demonstrativos contábeis. Listamos abaixo as principais medidas de enfrentamento ao vírus.

- Utilizar de videoconferências para realização de reuniões com fornecedores ou colaboradores idosos;

- Informatizar os procedimentos possíveis;

- Imunizar todos os manipuladores contra o vírus da Influenza;

- Dividir os colaboradores em duas equipes para evitar aglomeração, sendo que uma equipe vem pela manhã e outra à tarde;

- Desligar o ar condicionado e trabalhar com janelas abertas para arejar o local; 
- Higienizar diariamente os computadores com álcool específico;

- Promover uma palestra de orientação para todo o pessoal;

- Receber Feedback diário dos encarregados de setor sobre as medidas adotadas;

- Estabelecer que todo colaborador que se apresente enfermo deve imediatamente comunicar o setor pessoal;

- Proibir a entrada de estranhos e visitantes dentro do restaurante;

- Realizar instruções constantes sobre a importância e o procedimento correto de higienização das mãos;

- Proibir qualquer colaborador de fumar nas dependências do restaurante, mesmo antes ou depois do serviço;

- Orientar colaboradores a não irem embora sem tomar banho;

- Proibir qualquer funcionário de ir embora fardado, mesmo que seja só com uma peça do uniforme de manipulador, como a calça ou o calçado;

- Orientar os funcionários que, estando assintomáticos, não é necessário usar luvas ou máscaras enquanto manipulam alimentos. A correta higiene corporal, inclusive das mãos, é muito mais eficaz;

- Instalar pias de acionamento automático em pontos estratégicos.

- Sempre que reunir funcionários, fazer em locais abertos e arejados.

As UANs desempenham importante papel em termos de saúde pública, na medida em que afetam o estado nutricional e o bem-estar dos seus comensais por meio da qualidade do alimento que produzem. Desta forma, as práticas de prevenção ao contágio do COVID19 devem ser seguidas sobretudo por aqueles que desempenham atividades indiretas na produção das refeições para que o funcionamento da unidade não seja comprometido devido ao afastamento ou queda na produtividade dos funcionários da área administrativa decorrente de enfermidades adquiridas.

As medidas protetivas planejadas pela Subseção administrativa e contábil foram implementadas integralmente. No início, houve um pouco de resistência por parte dos colaboradores, revelando a necessidade de se realizar um trabalho de monitoramento e conscientização dos profissionais. Mas com o agravo do cenário da pandemia, os trabalhadores foram se alinhando ao plano de trabalho, pois percebiam que tais medidas eram importantes não apenas para a produção de alimentos seguros, mas para a manutenção da sua própria saúde e segurança.

\subsection{Subseção de Almoxarifado}

Responsável por acompanhar a demanda de insumos, realizar pedidos junto aos fornecedores e armazenar adequadamente os alimentos. Listamos abaixo as principais medidas de enfrentamento ao vírus.

- Gerenciar para que todas as entregas ocorram no mesmo dia;

- Diminuir a variedade de insumos pedidos;

- Dar preferência a fornecedores locais ou cooperativas de agricultura familiar;

- Disponibilizar máscaras para os colaboradores;

- Agilizar os recebimentos através de comissão específica;

- Solicitar aos fornecedores que mandem número reduzido de entregadores;

- Inspecionar se os entregadores adotam medidas preventivas de contaminação e se portam EPIs;

- Higienizar com agua sanitária diluída em água na proporção de $20 \mathrm{ml}$ para um litro de água todas as embalagens antes de entrarem para o estoque;

- Higienizar com água sanitária todas as frutas e hortaliças antes de irem para o estoque;

- Retirar os produtos das caixas de papelão, inclusive, os produtos cárneos;

- Não solicitar itens de difícil higienização;

- Exigir dos colaboradores o uso de macacão e luvas protetoras;

- Manter arejados os almoxarifados;

- Proibir que os colaboradores desse setor fiquem confinados, aglomerados ou conversando próximos uns dos outros. 
Nesta subseçao a implementação das medidas protetivas exigiu uma reestruturação do setor, inclusive com alocação de mais três funcionários neste posto de trabalho, pois a necessidade de higienizar rigorosamente cada insumo, antes de armazená-lo, aumentou significativamente as atividades do setor. Outra dificuldade encontrada pelo encarregado desta seção foi conciliar a rotina das diversas empresas fornecedoras, de modo que, entregassem sempre no dia programado. Sendo difícil coordenar todas as entregas para o mesmo dia, estabeleceu-se que as entregas ocorreriam sempre as segundas e quartas-feiras. Apesar das adequações necessárias, pode-se dizer que as medidas protetivas planejadas para o almoxarifado foram integralmente implementadas.

A Food and Agriculture Organization (FAO) juntamente com a OMS reforçam a manutenção da integridade da cadeia alimentar e a disponibilidade de insumos adequados e seguros para os consumidores. Desta forma, para manter o vírus fora do ambiente alimentar, o controle deve ser realizado tanto pelas indústrias de abastecimento de alimentos bem como pelas unidades produtoras de refeição, respeitando as medidas de distanciamento físico e aplicação de medidas rigorosas de higiene, sobretudo na etapa de recebimento e armazenamento da matéria-prima (FAO, 2020).

\subsection{Subseção de Açougue}

Responsável por retirar os produtos cárneos de acordo com o per capta estabelecido, realizar os cortes, os temperos e acondicionar até a retirada do produto pela equipe da cozinha. Listamos abaixo as principais medidas de enfrentamento ao vírus.

- Enfatizar a importância de se evitar hábitos pessoais inadequados à manipulação de alimentos, como: tossir, conversar e espirrar próximo ao alimento;

- Inspecionar se os colaboradores trocam diariamente os uniformes;

- Intercalar os dias de trabalho do efetivo do setor, diminuindo assim, a aglomeração de pessoas;

- Orientar os manipuladores a manter um metro de distância entre eles.

- Como nesse setor o ar condicionado não pode ser desligado, enfatizar a higienização diária do mesmo;

- Elaborar cardápios que exijam cortes de carne mais simples, rejeitando cardápios que exijam excesso de manipulação nas carnes;
- Enfatizar a importância da higiene corporal e do asseio;

- Exigir que os funcionários trabalhem com o uniforme completo, limpo e de cor clara;

- Exigir que no corte de carne, usem avental plástico, para evitar contaminação com sangue;

- Monitorar o correto uso dos EPIs.

As medidas acima citadas convergem com as "Orientações Gerais para Frigoríficos em Razão da Pandemia da COVID-19" publicada pelo Ministério da Agricultura, Pecuária e Abastecimento (BRASIL, 2020c). Neste manual há uma série de medidas direcionadas aos empregadores e aos trabalhadores para prevenir e diminuir o contágio da Covid-19 nos ambientes de trabalho, tendo como objetivo manter a normalidade de abastecimento alimentar garantindo o fornecimento de alimento seguro à população.

\subsection{Subseção de Cozinha}

Responsável por elaborar as refeições servidas no restaurante institucional. Listamos abaixo as principais medidas de enfrentamento ao vírus.

- Enfatizar a importância da higiene pessoal na manipulação de Alimentos;

- Aplicar diariamente, antes do início das atividades, Check List sobre apresentação pessoal dos manipuladores; para identificar se existe algum manipulador mal uniformizado, com cabelo ou barba grande, entre outros;

- Desaconselhar Hábitos Pessoais inadequados como tossir e espirrar próximo ao alimento;

- Proibir a conversa durante a manipulação de alimentos;

- Excetuando-se necessidades reais, os manipuladores não devem se ausentar da cozinha. Quando o fizerem, devem deixar o dólmã e o avental, além de higienizar as mãos ao sair e ao retornar.

- Apenas o encarregado da cozinha tem permissão de ausentar-se da cozinha para resolver situações corriqueiras, como buscar insumo no estoque, por exemplo.

- Inspecionar se os colaboradores trocam diariamente os uniformes; 
- Evitar a proximidade entre manipuladores, os mesmos devem, sempre que possível, manter uma distância mínima de um metro uns dos outros. Se necessário uma maior proximidade em razão da tarefa, deve-se evitar conversar, rir ou tocar no companheiro;

- Proibir a entrada de pessoas estranhas à cozinha. Visitantes mesmos autorizados devem adotar as mesmas políticas de prevenção dos demais manipuladores;

- Adotar cardápios mais simples que permitam a divisão da equipe em turnos e restrinjam a quantidade de manipulação sofrida pelo alimento;

- Criar um refeitório exclusivo para os manipuladores de alimento;

- Proibir que manipuladores experimentem os alimentos na palma da mão, usar colheres e higienizar antes de usar novamente.

- $\mathrm{O}$ alimento em espera deve ser mantido aquecido a $65^{\circ}$ em forno combinado ou resfriado a $5^{\circ} \mathrm{em}$ câmara frigorífica específica;

- Profissionais do refeitório não devem adentrar à cozinha para retirar os alimentos em espera.

Os cuidados com higiene pessoal, sobretudo a lavagem frequente e correta das mãos é uma das estratégias mais efetivas para reduzir o risco de transmissão e de contaminação pelo novo coronavírus. Dados da literatura mostram um elevado percentual de não conformidade no requisito higiene e conduta pessoal, como uso de adornos, esmalte, inadequações no uniforme, além de antissepsia inadequada das mãos (OLIVEIRA et al. 2020). Desta forma, as medidas necessárias para garantir que todos os colaboradores estejam procedendo adequadamente devem ser reforçadas, sendo aperfeiçoados também os procedimentos de higienização de superfícies, incluindo aquelas de maior contato, como maçanetas das portas, corrimãos (BRASIL, 2020a; FDA 2020b).

\subsection{Subseção de Refeitório}

Responsável por servir as refeições, receber os comensais e gerenciar o fluxo de pessoas que se alimentam no restaurante institucional. Listamos abaixo as principais medidas de enfrentamento ao vírus.

- Higienizar os talheres, envolver em guardanapo, depois ensacar e dispor sobre as mesas;
- Higienizar as mesas com álcool a 70\% logo após o comensal levantar;

- Retirar toalhas de mesa e demais enfeites e arranjos onde o vírus possa se prender;

- Manter o distanciamento entre comensais na fila para o buffet;

- Adotar o autosserviço para mitigar o contato físico entre manipuladores e comensais;

- Proibir que o comensal toque nos talheres e pegadores do buffet sem antes higienizar as mãos;

- Orientar a entrada dos comensais no refeitório para evitar aglomeração;

- Criar mais dois horários para as refeições, dividir os horários por setores da empresa, de acordo que não haja lotação, nem tampouco contato entre pessoas de setores de risco;

- Orientar que se sentem no máximo duas pessoas por mesa.

- Evitar conversa no refeitório;

- Colocar na caixa de som músicas agradáveis para quebrar o silêncio e a ansiedade;

- Evitar o uso de jarras sobre as mesas e outras coisas compartilhadas. Preferir o uso de copo plástico para o suco.

- Disponibilizar água mineral para o público, em garrafas ou copos descartáveis com 200ml de conteúdo. São unitários e podem ser higienizados antes do consumo;

- Lavar pratos e talheres na máquina de lavar louça industrial ou se lavados à mão secar e passar álcool a 70

- Manter os pratos em estufa aquecidos a 65 graus, podendo ser utilizado um forno combinado para essa função;

- Servir a comida em travessas rasas de modo que haja várias reposições e se evite o excesso de tempo exposto no buffet;

- Solicitar que as pessoas venham para o restaurante somente no seu horário de almoço, evitando assim aglomeração de pessoas na porta do refeitório e também no interior dele; 
- Criar um fluxo em que as pessoas sejam obrigadas a passar pela pia de higienização de mãos, antes de ir ao balcão.

- Manter as pias abastecidas de sabonete líquido antisséptico, e papel toalha não reciclado;

- Evitar a aglomeração de pessoas diante das pias de higienização de mãos;

- Impedir que comensais tragam quentinhas ou vasilhames para dentro do restaurante ou que através delas saiam com alimentação;

- Adotar o uso de máscaras tipo face shield para os garçons que atuam no trato direto com os comensais e na reposição do alimento;

- Impedir que os garçons fiquem aglomerados, conversando entre si ou com os comensais. Exigir que adotem sempre uma postura proativa visando manter o ambiente limpo e organizado.

Esta subseção foi a primeira que implementou as medidas planejadas, afinal esta é a única subseção visualizada pelos clientes. Nos primeiros meses de pandemia observou-se uma queda na procura por alimentação no restaurante institucional, devido principalmente ao temor que as pessoas adquiriram em freqüentar espaços públicos. Logo, era fundamental implementar imediatamente medidas que transmitissem segurança aos comensais, trazendo-os de volta aos restaurantes institucionais.

De todo modo, as medidas implementas atendem as recomendações do FDA por meio do check list para estabelecimentos produtores de alimentos durante a pandemia de Covid-19 que estabelece que a UAN deve orientar o comensal a manter um bom controle de higiene e distanciamento social, por meio de medidas que garantam o distanciamento entre os comensais durante a distribuição e o consumo da refeição, além de evitar o manuseio de utensílios comuns por pessoas que não tenham higienizado as mãos (FDA, 2020a).

\subsection{Subseção de Copa}

Responsável por receber e higienizar os utensílios que retornam do refeitório do Restaurante institucional. Listamos abaixo as principais medidas de enfrentamento ao vírus.

- Instruir copeiros a utilizarem máscara tipo face shield, bem como, máscaras descartáveis para sua proteção;
- Instruir copeiros a utilizarem avental de plástico e luvas de borracha para evitar que ao receberem os utensílios sujos, se contaminem;

- Instruir copeiros que não se aproximem muito do bistrô de recebimento, nem tampouco, converse com aquele que estiver entregando a louça utilizada;

- Sendo a copa um lugar fechado, instruir os copeiros que trabalhem afastados uns dos outros, evitando conversa desnecessária;

- Instruir os copeiros quanto ao uso adequado de sabão líquido na higienização dos materiais, seja através de máquina de lavar louças ou lavagem manual;

- Instruir quanto à correta higienização de utensílios lavados a mão;

- Proibir que utensílios permaneçam na copa, entre uma refeição e outra;

- Aspergir álcool em gel e ensacar os utensílios após saírem da máquina de lavar louças ou da higienização manual;

- Assegurar que os copeiros estejam trocando diariamente de uniformes.

Embora os manipuladores sejam encorajados a fazer o uso de máscaras de proteção, os mesmos são orientados que o uso das máscaras não reduz a necessidade de intensificação dos hábitos de pessoal, inclusive da lavagem de mãos, e de manter o distanciamento de 1 metro entre as pessoas, sempre que a atividade permitir, conforme preconizado pela Nota Técnica $N^{\circ} 47$ da ANVISA (BRASIL, 2020d).

\subsection{Subseção Depósito de Materiais}

Responsável por retirar da copa e armazenar os utensílios de salão e cozinha, enquanto estes não estão sendo utilizados. Listamos abaixo as principais medidas de enfrentamento ao vírus.

Instruir o estoquista a utilizar avental e luvas de borracha para evitar contaminar-se ou contaminar os materiais;

- Evitar aglomeração de pessoas no ambiente. Desligar o ar condicionado e deixar o ambiente arejado através de ventilação natural;

- É proibido armazenar ou manter no setor qualquer outro material que não seja utensílio de copa, cozinha, salão ou congêneres; 
- Proibir que qualquer tipo de refeição seja realizada neste ambiente;

- Proibir que pessoas estranhas ao setor permaneçam no mesmo;

- Agilizar as retiradas de materiais, evitando conversas desnecessárias no ambiente;

- Definir o horário em que cada encarregado de setor irá buscar os utensílios de que precisa.

A Higiene na Manipulação de Alimentos sempre foi prioridade no Serviço de Alimentação, ou seja, as diretrizes recomendadas pela Anvisa e pelo Ministério da Saúde através de suas Resoluções e Portarias, sempre foram respeitadas. Os documentos internos do restaurante, como Manual de Boas práticas e POP, são alinhados a esses regimentos, fato verificado pelas constantes auditorias recebidas. Isso quer dizer que, aquilo que os órgãos fiscalizadores preconizam sobre Higiene das Instalações, dos Móveis e utensílios, dos Manipuladores, de Controle de Pragas e Vetores, entre outros, encontra-se implementado no Restaurante, estando este, comprovadamente de acordo com a Legislação.

Comprovando tal afirmativa, antes da pandemia, o Restaurante institucional alcançava um padrão de $95 \%$ de conformidade às exigências da $\mathrm{RDC} \mathrm{n}^{\circ} 216$, demonstrando o seu comprometimento com a higiene e a segurança na produção e distribuição de alimentos. Com o incremento das novas exigências, em consequência ao enfrentamento da disseminação da Covid-19 em serviços de alimentação, essa percentagem de adequação e conformidade sofreu uma ligeira queda para $90 \%$.

De todo modo, as mudanças observadas no restaurante diante do novo contexto do COVID 19 estão de acordo com os órgãos de saúde e coincidem com a nota técnica no 48 da Anvisa (BRASIL, 2020a). As mudanças se referem principalmente à recomendação de evitar a aglomeração e o contato muito próximo entre pessoas. Atualmente, o restaurante não atende a todo o efetivo, restringindo o atendimento para apenas os funcionários que estão trabalhando no plantão, totalizando aproximadamente 100 pessoas por dia. Com isso o efetivo de colaboradores do restaurante também pode ser flexibilizado, permitindo escala de funcionários por setor. Cada setor da Empresa tem seu horário de refeição, e em cada mesa sentam apenas duas pessoas. Outras mudanças se referem ao afastamento de colaboradores pertencentes ao grupo de risco, à higienização das mãos antes de se servir, proibição de visitas técnicas e agendamento de entregas de insumos em dias pré-determinados.

Uma mudança notória durante a pandemia foi a consciência dos colaboradores e comensais no que se refere à relevância dos cuidados com higiene como prática fundamental para a prevenção. Como reflexo dessa nova percepção, observou-se um aumento no rigor na execução das tarefas, bem como na monitoração por parte da chefia. Essas novas práticas geram benefícios não só para os colaboradores, mas se estende aos comensais, considerando que as práticas adequadas executadas por um motivam o outro a realizar as condutas recomendadas.

\section{CONCLUSÃO}

O restaurante institucional estudado adotou medidas de prevenção ao novo coronavírus através do planejamento de atividades que corroboram com as orientações emanadas pela ANVISA e demais órgãos de saúde. As medidas de enfrentamento ao Covid-19, provenientes do documento intitulado de "Medidas de Prevenção ao Covid-19", elaborado pela empresa após reunião, enumerou uma série de medidas que foram adotadas e inseridas ao check list de cada setor.

Após esse planejamento, as condutas foram implementadas e supervisionadas, observando-se adequação aos padrões de segurança alimentar, garantia da saúde de todos os colaboradores, além de promover motivação e consciência da importância dos hábitos pessoais de higiene por toda a equipe.

Para muitos, as medidas adotadas pelo Restaurante Institucional estudado soam como rigorosas e exageradas. Contudo, o objetivo das medidas enérgicas adotadas é diminuir os riscos de contaminação pelo coronavírus, garantindo a saúde e a segurança alimentar dos colaboradores e dos comensais. Quando essa fase de pandemia passar, ficará o aprendizado e a consciência de que, por mais organizado que seja um serviço de alimentação, sempre existirá campo para melhorias.

\section{REFERÊNCIAS}

BRASIL. RDC n ${ }^{\circ}$ 216, de 15 de Setembro de 2004. Dispõe sobre o Regulamento Técnico de Boas Práticas para Serviços de Alimentação. Brasília, 2004. Diário Oficial da República Federativa do Brasil.

Documento orientativo para produção segura de alimentos durante a pandemia de Covid-19. Brasília: [s.n.], 2020. Agência Nacional de Vigilância Sanitária. Nota técnica No 48/2020/SEI/GIALI/GGFIS/DIRE4/ANVISA. Disponível em: <http://portal.anvisa.gov.br/ documents/219201/4340788/NOTA_TECNICA_N

_48_Boas_Praticas_e_Covid_19_Revisao_final. pdf/ba26fbe0-a79c-45d7-b8bd-fbd2bfdb2437> 
O que é coronavírus? (COVID19). Brasília, 2020. Disponível em: <https: //coronavirus.saude.gov.br/>

Orientações Gerais para Frigoríficos em Razão da Pandemia da COVID-19. Brasília, 2020. Disponível em: <https://www.gov.br/ agricultura/pt-br/mapacontracoronavirus/documentos/ manual-orientacoes-gerais-para-frigorificos-em- razao-da-pandemia-da-covid-19/view>

Uso de luvas e máscaras em estabelecimentos da área de alimentos no contexto do enfrentamento do COVID-19. Brasília, 2020. Nota técnica No 47/2020/SEI/GIALI/GGFIS/DIRE4/ANVISA. Disponível em: <http://portal.anvisa.gov.br/ documents/219201/4340788/NOTA_TECNICA N_47.2020.SEI.GIALI_0_uso_de_EPIs.pdf/ 41979d87-50b8-4191-9ca8-aa416d7fdf6e.>

CEARÁ. Governo do Estado do Ceará. Decreto No 33631 de 20/06/2020. Prorroga o isolamento social no Estado do Ceará, renova a política de regionalização das medidas de isolamento social, $e$ dá outras providências. Fortaleza, 2020. Serie 3. Ano XII, $\mathrm{N}^{\circ} 128$.

FAO. Protecting the food supply chain from COVID-1. Roma, 2020. Disponível em: <http://www.fao.org/fao-who-codexalimentarius/ news-and-events/news-details/en/c/1270223/>

FDA. Best Practices for Re-Opening Retail Food Establishments During the COVID-19 pandemic. Washington, 2020. Disponível em: <https: //www.fda.gov/food/food-safety-during-emergencies/ best-practices-re-opening-retail-food-establishments। -during-covid-19-pandemic>

. Best Practices for Retail Food Stores, Restaurants, and Food Pick-Up/Delivery Services During the COVID-19 Pandemic. Washington, 2020. Disponível em: <https: //www.fda.gov/media/136811/download>

FIOCRUZ. Plano de contingência da Fiocruz diante da pandemia da doença pelo SARS-CoV-2 (COVID-19). Rio de Janeiro: FUNDAÇÃO OSWALDO CRUZ, 2020. v. 1. Versão 1.4, de 22 de abril de 2020.

OLIVEIRA, A. M. C.; SOUSA, P. V.; ALVES, A. A. S.; MEDEIROS, S. R. A.; MENDONÇA, M. J. do $\mathrm{N}$. Adequação de serviços de alimentação às boas práticas de fabricação. Conexões-Ciência e Tecnologia, v. 14, n. 1, p. 30-36, 2020.
OLIVEIRA, T. C.; ABRANCHES, M. V.; LANA, R. M. (in) segurança alimentar no contexto da pandemia por sars-cov-2. Cadernos de Saúde Pública, SciELO Public Health, v. 36, n. 1, p. e00055220, 2020.

WHO. Coronavirus disease (COVID-19) Pandemic. Geneva, 2020. Disponível em: <https://www.who.int/ emergencies/diseases/novel-coronavirus-2019> 